\title{
GERAÇÃO Y: COMO ATRAIR E RETER?
}

\author{
Generation Y: how to attract and reter?
}

\author{
Kamilla Radech de Lima ${ }^{1}$ \\ Geneia Lucas dos Santos ${ }^{2}$ \\ Recebido em: 03 jul. 2017 \\ Aceito em: 02 ago. 2017
}

Resumo: A geração $Y$, também conhecida por geração do milênio, é representada por indivíduos nascidos entre os anos de 1980 e 1995. Caracterizada pela velocidade de acesso às informações e intimidade com os meios tecnológicos, essa geração possui uma nova visão em relação ao trabalho e, por consequência, novas expectativas. Diante disso, surge a necessidade de adaptar a gestão das empresas de maneira que se torne possível a atração, desenvolvimento e retenção desses profissionais dentro das organizações. Neste sentido, o estudo tem como objetivo identificar as características da geração $Y$, bem como os fatores que promovem a sua satisfação, motivação e permanência no emprego. Para que fosse possível atingir os objetivos propostos, elaborou-se uma pesquisa de caráter exploratório e descritivo que fora aplicada por meio de questionário fechado veiculado por meio de redes sociais. Os resultados obtidos demonstraram que a geração Y é movida por desafios, demonstra grande interesse em adquirir novos conhecimentos e espera reconhecimento, credibilidade e crescimento profissional dentro das organizações.

Palavras-Chave: Geração Y. Comportamento. Gestão de pessoas.

Abstract: The generation $Y$, also known by generation of the millennium, is represented by individuals born between the years of 1980 and 1995. Characterized by the speed of access to information and intimacy with technological means, this generation has a new vision in relation to work and, consequently, new expectations. Faced with this, there is a need to adapt the management of companies in a way that makes it possible to attract, develop and retain these professionals within organizations. In this sense, the research aims to identify the characteristics of generation $Y$, as well as the factors that promote their satisfaction, motivation and permanence in employment. In order to achieve the proposed objectives, an exploratory and descriptive research was developed and applied through a closed questionnaire carried out through social networks. The results show that the $Y$ generation is driven by challenges, shows great interest in acquiring new knowledge and expects recognition, credibility and professional growth in organizations.

\footnotetext{
${ }^{1}$ Pós-graduanda em Gestão Estratégica de Pessoas (UNIARP) e graduada em Administração (UNIARP). E-mail: kamiradech@gmail.com.

2 Doutoranda em Administração - Universidade Federal do Rio Grande do Sul (UFRGS) na linha de pesquisa de Gestão de Pessoas, Mestre em Administração de Empresas (Universidade do Sul de Santa Catarina - UNISUL Fpolis/SC); Graduada em Psicologia (Universidade Alto Vale do Rio do Peixe - UNIARP) e em Administração de Empresas (Universidade do Contestado - UnC Caçador/SC). E-mail: geneia@uniarp.edu.br.
} 
Keywords: Generation Y. Behavior. People management.

\section{INTRODUÇÃO}

O atual ambiente corporativo apresenta importantes mudanças decorrentes da globalização e do avanço tecnológico. Este novo cenário, mais competitivo e cada vez mais complexo, levou os gestores à busca por um melhor gerenciamento do capital intelectual dentro das organizações (LACOMBE, 2005). Neste sentido, o ato de atrair e reter profissionais pertencentes à Geração $Y$ tornou-se objeto de estudo de interesse organizacional, uma vez que, de acordo com Loiola, apud Dos Santos et al (2011), os jovens pertencentes a esta geração possuem a tendência de fazer várias coisas ao mesmo tempo, gostam de variar e são estimuladas por desafios e oportunidades, além disso possuem alta capacidade de interação com novas tecnologias, lidando de maneira natural com a velocidade das mudanças. (LINPKIN e PARRYMORE, 2010).

A Geração Y, de acordo com Erickson (2011), é composta por indivíduos nascidos entre os anos de 1980 e 1995 e uma de suas características está relacionada à motivação pela busca de novos desafios e rápida ascensão profissional. Os jovens pertencentes a esta geração são muito exigentes e gostam de sentir-se valorizados. Eles necessitam de feedback constante e, se não percebem reconhecimento na organização onde atuam, buscam novos horizontes. Este comportamento acaba por aumentar a rotatividade nas empresas (LINPKIN e PARRYMORE, 2010). Os jovens pertencentes a esta geração são muito exigentes e gostam de sentir-se valorizados, eles necessitam de feedback constante e, se não percebem reconhecimento na organização onde atuam, buscam novos horizontes. Este comportamento acaba por aumentar a rotatividade nas empresas (LINPKIN e PARRYMORE, 2010).

Considerando que o sucesso de uma organização depende de seu capital intelectual, observa-se a necessidade das empresas em adaptar-se e entender o comportamento desta geração, de maneira que torne possível atender às suas expectativas, promovendo assertividade nas ações destinadas à atração, desenvolvimento e retenção destes profissionais, pois eles possuem a capacidade de favorecer o desempenho das empresas no mercado. Neste sentido a pesquisa teve como objetivo identificar fatores que promovem a atração e retenção em profissionais pertencentes à Geração Y.

\section{GERAÇÃO Y}

De Acordo com Bauer (2010), a geração Y é a primeira que já nasceu utilizando a internet e fazem parte dela os nascidos entre os anos 80 e 90.

Neste mesmo sentido, Perrone et al. (2012) afirma que os indivíduos pertencentes a 
geração Y nasceram entre o final dos anos de 1980 e início de 1990. Desenvolveram sua maturidade em tempos prósperos devido a globalização e hoje representam um real desafio às organizações que buscam motivar e conquistar seu comprometimento. Esta geração é mais cínica que suas antecessoras e possui tendência a não aceitar uma retórica da administração que não esteja baseada em ações.

Para identificar as características desta geração é necessário compreender quem faz parte dela. Desta forma Bauer (2010) afirma que esta geração é a primeira que já nasceu utilizando a internet e fazem parte dela os nascidos entre os anos 80 e 90.

\begin{abstract}
[...] a Geração Y inclui nascidos entre o final dos anos 1980 e início dos anos 1990 possíveis filhos de casais da Geração Boomer -, que saíram de casa mais tarde que as gerações anteriores. Enquanto a Geração X foi moldada pela desindustrialização e pela queda do comunismo, a Geração Y desenvolveu sua maturidade durante a guerra ao terror, lendo Harry Potter e desfrutando de tempos relativamente prósperos devido à globalização. A Geração Y oferece um desafio real às organizações que buscam motivar e conquistar o comprometimento de seus empregados. Esta Geração é mais cínica que a anterior e menos inclinada a aceitar uma retórica da administração que não esteja apoiada em ações. (PERRONE et al. 2012, p. 4)
\end{abstract}

Em relação a geração Y, Erickson (2011) afirma que ao longo da última década, a Geração Y, que é também denominada Geração do Milênio, ingressou na força de trabalho. Eles nasceram entre os anos de 1980 e 1995 e representam uma grande proporção da população mundial. A enormidade dessa coorte geracional significa que ela irá influenciar de maneira significativa o mundo do trabalho.

Essa geração foi estimulada e influenciada pela velocidade de acesso a um expressivo volume de informações provenientes da internet, pelas ações de videogames e pelas inúmeras atividades diárias. A importância está no que eles sabem fazer, pois os membros desta geração valorizam muito a competência. (KHOURI, 2010)

No mesmo sentido, Huntley apud Wada e Carneiro (2010), afirma que as crianças da geração $Y$ nasceram e foram criadas em um ambiente com grande diversidade de atividades a serem desenvolvidas, pois os pais desta geração passavam o dia trabalhando e preocupavamse em ocupar o tempo de seus filhos com tarefas educativas visando seu desenvolvimento no futuro. Buscavam assegurar-se de que seus filhos estavam sendo bem cuidados e educados, participavam ativamente de sua vida escolar e, posteriormente, da escolha do curso superior. A geração $Y$ foi criada com o ideal de fazer diferença no mundo e incentivada sempre a participar de atividades que desenvolvessem o senso cívico e a responsabilidade social.

\title{
CARACTERÍSTICAS DA GERAÇÃO Y
}

Para esta geração, é de extrema importância a percepção de que estão crescendo intelectual e profissionalmente, isso porque receberam, desde cedo, estímulos em abundância 
e passaram a valorizar a aprendizagem. Desta forma levam essa necessidade de continuar desenvolvendo conhecimento para dentro das organizações em que atuam. (KHOURI, 2010)

De acordo com McCrindle (2002) a geração Y se difere das demais por focar em objetivos a curto prazo e Huntley (2006) afirma que eles são influenciados por padrões estabelecidos pelos veículos de comunicação de massa e possuem uma ansiedade por viver e querer tudo ao mesmo tempo.

De acordo com Sennett (1998) apud Perrone et al. (2012, p. 4) essa geração possui uma tendência a não esperar comprometimento pois eles vivenciaram a agressividade do capitalismo e a transformação de marcas, passando a não confiar plenamente em projetos de longo prazo ou futuros previsíveis. Desta maneira, é inadequado utilizar o modelo tradicional de gestão com pessoas que desejam trabalhar com objetivos imediatos, sendo preferível dar ênfase na criatividade e inovação destes profissionais.

Para Erickson (2011) o comportamento desta geração no trabalho pode parecer impróprio no ponto de vista de outras gerações. Eles são audazes e diretos, emitem suas opiniões com naturalidade e facilidade, muitas vezes sem considerar a hierarquia e os protocolos "apropriados" para isto.

As pessoas integrantes desta geração são consideradas ambiciosas, individualistas, decididas, coletivas e com um bom nível de formação, na maioria das vezes. Observa-se também que são preocupadas com o meio ambiente e direitos humanos, geralmente agem por conta própria e não aguardam autorização de superiores para isso. Possuem a tendência de fazer várias coisas ao mesmo tempo, gostam de variar e são estimuladas por desafios e oportunidades. Convivem bem com as diferenças, pois aceitam as diversidades. (LOIOLA, apud DOS SANTOS et al, 2011)

De acordo com Erickson (2011) a geração Y aprende por meio de interações pessoais, por isso, quando algum $Y$ manifesta interesse em receber mais feedback ele está expressando o seu desejo em aprender mais. Eles esperam compartilhar ideias, informações, sugestões ou treinamento.

Para Dos Santos et al (2011) a geração Y possui vontade de aprender e trabalhar, buscando o máximo de conhecimento nas empresas em que atuam. É considerada a geração com maior potencial de crescimento quando comparada as anteriores, pois são ágeis, proativos e apresentam motivação e produtividade elevadas. São brilhantes e dominam as tecnologias, sendo esta última característica muito importante no atual ambiente empresarial e que foi possível graças aos estímulos virtuais recebidos desde a infância, proporcionando o desenvolvimento do pensamento sistêmico e globalizado.

Em relação à tecnologia Linpkin e Parrymore (2010) afirmam que, ao contrário das gerações antecessoras que eram analógicas, a geração Y é digital e possui alta capacidade de interação com tecnologias, lidando de maneira natural com a velocidade das mudanças nos 
meios de comunicação eletrônicos.

Por outro lado, essa grande quantidade de estímulos recebidos na infância acabou por privar-Ihes algumas habilidades sociais e psicológicas, tendo por consequência a dificuldade em aceitar críticas. Esta geração espera um tratamento igualitário em relação aos seus gestores e o reconhecimento e utilização de sua competência no cumprimento de metas estabelecidas são algumas de suas expectativas (HUNTLEY, 2006).

Os indivíduos pertencentes a geração $Y$ possuem uma relação diferente com hierarquia, horários e produtividade. Eles preferem vestir a própria camisa à da empresa e para sua permanência no trabalho é essencial que exista feedback constante dos gestores. A geração Y busca mais do que salários e benefícios, eles são movidos por uma continuidade de desafios e seu comprometimento e permanência na empresa também dependem da capacidade de inovação da organização.

Erickson (2011, p. 177) elenca dez questões importantes para gerenciar a Geração Y:

1 Seja simpático. Adote o modo de se expressar dessa geração, quando possível, particularmente durante o processo de recrutamento. Deixe claro quando eles devem adotar o seu.

2 [...] Os pais da geração Y são parte inevitável do processo. Elabore mensagens que expliquem por que sua empresa é um ótimo local para os filhos trabalharem. Esteja preparado para as preocupações deles.

3 Gerencie o desempenho por tarefas, não pelo tempo. Sempre que possível, adote turnos, trabalho assíncrono e cronogramas flexíveis.

4 Invista em tecnologia e em suas próprias qualificações tecnológicas. Tente novas abordagens. Maximize a tecnologia para criar processos eficientes.

5 Oriente gerentes de primeira linha quanto ao essencial para gerenciar os Y. Eles requerem mesmo mais tempo do que qualquer outro empregado, sobretudo por procurarem gerentes que queiram ensinar.

6 Incentive o compartilhamento de conhecimento. A geração Y se surpreende se não for estimulada a conseguir as informações de que precisa.

7 Encoraje os boomers a serem mentores dos Y. A geração $Y$ aprecia os boomers. Facilite sua vida, peça aos boomers para servir de mentores e assumir algumas responsabilidades de ensino.

8 Desafie os Y com tarefas que requeiram "imaginação". Não especifique demais como fazer o trabalho.

9 Projete as trajetórias da carreira com frequentes movimentos laterais. Eles não desejam necessariamente subir, mas estarão engajados se tiverem novas coisas para fazer.

10 Proporcione oportunidades de aprendizado de alta qualidade. A oportunidade de aprender é a prioridade dos Y.

Para Dos Santos (2011) os jovens talentos pertencentes a geração Y têm consciência de sua importância no processo produtivo e por isso buscam a satisfação de suas pretensões materiais, motivacionais, pessoais ou profissionais. Eles estão revolucionando o ambiente organizacional porque possuem este poder, uma vez que são bem-sucedidos e contam com alto nível de formação, são criativos e demonstram facilidade ao utilizar a tecnologia. Esta geração deseja transformar o relacionamento organizacional, pois possuem aspirações de 
novas experiências e de reconhecimento, preocupam-se com o meio ambiente e têm fortes valores morais.

Torna-se evidente o quão benéfico pode ser a participação efetiva dos profissionais da geração Y no funcionamento das organizações. Neste sentido Erickson (2011) diz que clientes satisfeitos passam a valorizar o produto e abastecer a empresa por meio de capital, possibilitando recompensar os acionistas, mas, além disso, proporcionar treinamento e estímulos aos colaboradores que visam a melhoria da organização em benefício dos clientes. Isso se chama ciclo da prosperidade e é possível afirmar que a geração Y está pronta para ele, basta que os gestores saibam como motivar estes profissionais.

\section{METODOLOGIA}

Este estudo foi realizado por meio da utilização de dados qualitativos e quantitativos. De acordo com Oliveira (2005) a abordagem quantitativa visa a validação de hipóteses através de dados estruturados e estatísticos obtidos por meio de informações coletadas através de questionários, enquanto a pesquisa qualitativa pode ser caracterizada como sendo uma tentativa de se explicar em profundidade o significado e as características dos resultados obtidos.

É possível considerar a pesquisa como sendo descritiva que de acordo com Gil (2002) tem como objetivo principal a descrição das características de determinada população ou fenômeno ou o estabelecimento de relação entre variáveis. Quanto aos procedimentos adotados, inicialmente efetuou-se pesquisa bibliográfica, desenvolvida com base em material já elaborado, constituído principalmente de livros e artigos científicos. Posteriormente procedeu-se levantamento de dados através da interrogação direta de pessoas pertencentes ao grupo que se desejava conhecer, para que fossem obtidas conclusões correspondentes aos dados coletados (GIL, 2002).

A técnica de coleta de dados utilizada é do tipo Survey, que, de acordo com Fonseca (2002), se caracteriza pela obtenção de dados ou informações sobre as características ou as opiniões de determinado grupo de pessoas que representam certa população a ser estudada, tendo um questionário como instrumento de pesquisa. Desta maneira, fora aplicado questionário direcionado e estruturado, com 17 perguntas fechadas e 1 pergunta aberta, elaborado através da ferramenta Google Forms.

Os dados foram coletados por meio do método denominado 'bola de neve', sendo o convite para participação veiculado por meio das redes de contatos dos envolvidos no estudo. Segundo Baldin e Munhoz (2011), essa técnica é uma forma de amostra não probabilística utilizada em pesquisas onde os participantes iniciais de um estudo indicam novos participantes que por sua vez indicam novos participantes e assim sucessivamente. Desta forma é atingido o 
"ponto de saturação", momento em que os novos entrevistados passam a repetir os conteúdos já obtidos, não acrescentando dados relevantes à pesquisa.

Segundo Malhotra (2001, p.155), “a pesquisa qualitativa proporciona uma melhor visão e compreensão do contexto do problema, enquanto a pesquisa quantitativa procura quantificar os dados e aplica alguma forma da análise estatística". Desta forma, como procedimento para análise de dados qualitativos efetuou-se a interpretação das informações coletadas através de pesquisa bibliográfica e quanto aos dados quantitativos foram utilizadas análises estatísticas para sua interpretação.

\section{DESCRIÇÃO E ANÁLISE DOS RESULTADOS}

Participaram da pesquisa 251 voluntários, sendo que 52 deles nasceram antes de 1980, 152 entre os anos de 1980 e 1995 e 47 pessoas nasceram após o ano de 1995. Considerando que o objetivo da pesquisa era identificar fatores que promovem a atração e retenção em profissionais pertencentes à geração $Y$, apenas aqueles nascidos entre 1980 e 1995 foram direcionados a sessão seguinte, ou seja, os 152 indivíduos pertencentes a esta geração, sendo 89 mulheres e 63 homens.

Dentre os respondentes, 57,2\% possuem pós-graduação, 25,7\% já concluíram o nível superior, $11,2 \%$ possuem nível superior incompleto e os outros 5,9\% apresentaram escolaridade entre ensino fundamental incompleto e ensino médio completo. Os altos níveis de formação apresentados pela maioria confirmam o interesse na busca por conhecimento, característica desta geração.

O tempo de atuação destes profissionais nas organizações apresentou certa variação, $44,8 \%$ dos entrevistados estão no atual emprego a cerca de 3 anos ou menos, sendo que 22 pessoas ocupam o atual posto a menos e um ano e 46 entrevistados estão de um a três anos na mesma organização. Dentre os entrevistados $19,7 \%$ dos indivíduos atuam na mesma organização de 3 a 5 anos, 19,1\% trabalham de cinco a dez anos na mesma instituição, 7,2\% deles está há mais de 10 anos no mesmo trabalho, e os outros 9,2\% não estão trabalhando no momento. A maioria dos entrevistados (64.5\%) está no atual emprego há menos de 5 anos, fato que demonstra mais uma das características desta geração apontada por diversos autores.

Os Y's não possuem a mesma linha de pensamento das gerações anteriores que permaneciam por anos e se aposentavam trabalhando em uma única organização, eles permanecem no emprego até o momento em que se sentem valorizados e desafiados, caso não estejam satisfeitos, buscam por novas oportunidades (OLIVEIRA, 2010).

Ao serem questionados sobre a importância dada pelas organizações às suas opiniões, 19,1\% dos entrevistados disseram que as instituições sempre consideram seus pontos de vista, $25,7 \%$ disseram que isso ocorre com frequência, $34,2 \%$ deles afirmaram que as vezes suas 
opiniões são consideradas, $15,1 \%$ disseram que quase nunca e os outros 5,9\% relataram que suas opiniões nunca são consideradas. A importância dada à opinião destes colaboradores é fator importante na sua motivação e permanência na empresa, pois eles desejam sentir-se parte importante e ativa dentro das organizações onde atuam, necessitam de novas experiências seguidas do feedback constante de seus superiores para que se mantenham engajados e determinados a cumprir metas e atingir objetivos.

A busca constante por novos desafios (ERICKSON, 2011) confirmou-se no momento em que os representantes da geração $Y$ foram questionados em relação a isso. A maioria dos entrevistados busca por tarefas desafiadoras, sendo que $36,8 \%$ dos respondentes afirmaram que estão sempre na busca por novos desafios, 40,1\% tiveram a opção frequentemente como resposta, $19,1 \%$ disseram que as vezes buscam por desafios e apenas 3,9\% disseram que quase nunca o fazem.

Os Y's gostam de ter autonomia na resolução de problemas, prova disso foi o resultado obtido ao questioná-los se costumam resolver contratempos sem precisar comunicar seus gestores. Grande parte dos respondentes, $71,1 \%$, disse que costuma agir assim na maioria das vezes, sendo que $25,7 \%$ afirmaram que sempre agem por conta própria, 45,4\% disseram fazer isso com frequência. Dentre os entrevistados, $23,7 \%$ relataram as vezes resolver problemas sem precisar comunicar seu superior, 4,6\% indivíduos disseram quase nunca agir assim, enquanto apenas 0,7\% afirmou nunca agir sem o conhecimento do gestor. Esse fator está relacionado à algumas características da geração: eles gostam de possuir autonomia, sentemse capazes de resolver conflitos e problemas sozinhos. Além disso, a Geração Y não lida muito bem com a hierarquia e não aceitam críticas com facilidade, desta forma preferem evitá-las, solucionando os problemas antes mesmo de recebê-las.

Esses fatores são apresentados no próximo questionamento, onde perguntou-se sobre sua principal dificuldade no ambiente de trabalho. Foram obtidas as seguintes respostas: $23 \%$ das pessoas afirmaram que sua principal dificuldade no trabalho está relacionada à aceitação de críticas, $11,8 \%$ disseram que possuem dificuldade para seguir regras, 31,6\% relataram que focar em objetivos a longo prazo é seu principal obstáculo, 22,4\% têm dificuldade para relacionar-se com colegas de trabalho e 11,2\% disseram que o mais difícil é respeitar a hierarquia. Boa parte deles não lida bem com objetivos estabelecidos a longo prazo, uma vez que costumam ser imediatistas e ansiosos, uma solução para esta dificuldade seria fracionar o objetivo final estabelecendo metas a curto prazo de maneira a mantê-los engajados no trabalho. A geração $Y$ apresenta-se um pouco individualista, mas trabalha bem em grupo, uma maneira de aproveitar seu desempenho de maneira coletiva é a troca de conhecimentos entre os profissionais. Eles precisam receber críticas como uma oportunidade de melhoria, apenas apontar seus erros sem mostrar uma melhor maneira de agir não lhes convence. Desafiá-los a fazer melhor é uma maneira de corrigir e ao mesmo tempo motivar estes 
profissionais.

Ao serem questionados em relação as suas expectativas ao escolher uma organização para se trabalhar, observa-se que as respostas foram bem coerentes com os comportamentos dos jovens da Geração Y. Entre os entrevistados, 53,3\% disseram que o que mais consideram na escolha de uma empresa são o reconhecimento e a possibilidade de desenvolvimento profissional, 20,4\% consideram a importância de conciliar a vida pessoal com a vida profissional, $15,1 \%$ preocupam-se mais com o salário oferecido, 10,5\% com um bom ambiente de trabalho e $0,7 \%$ considera a oferta de cursos e treinamentos, conforme é possível observar no gráfico 1:

Gráfico 1 - Fatores que determinam a escolha de uma organização para trabalhar.

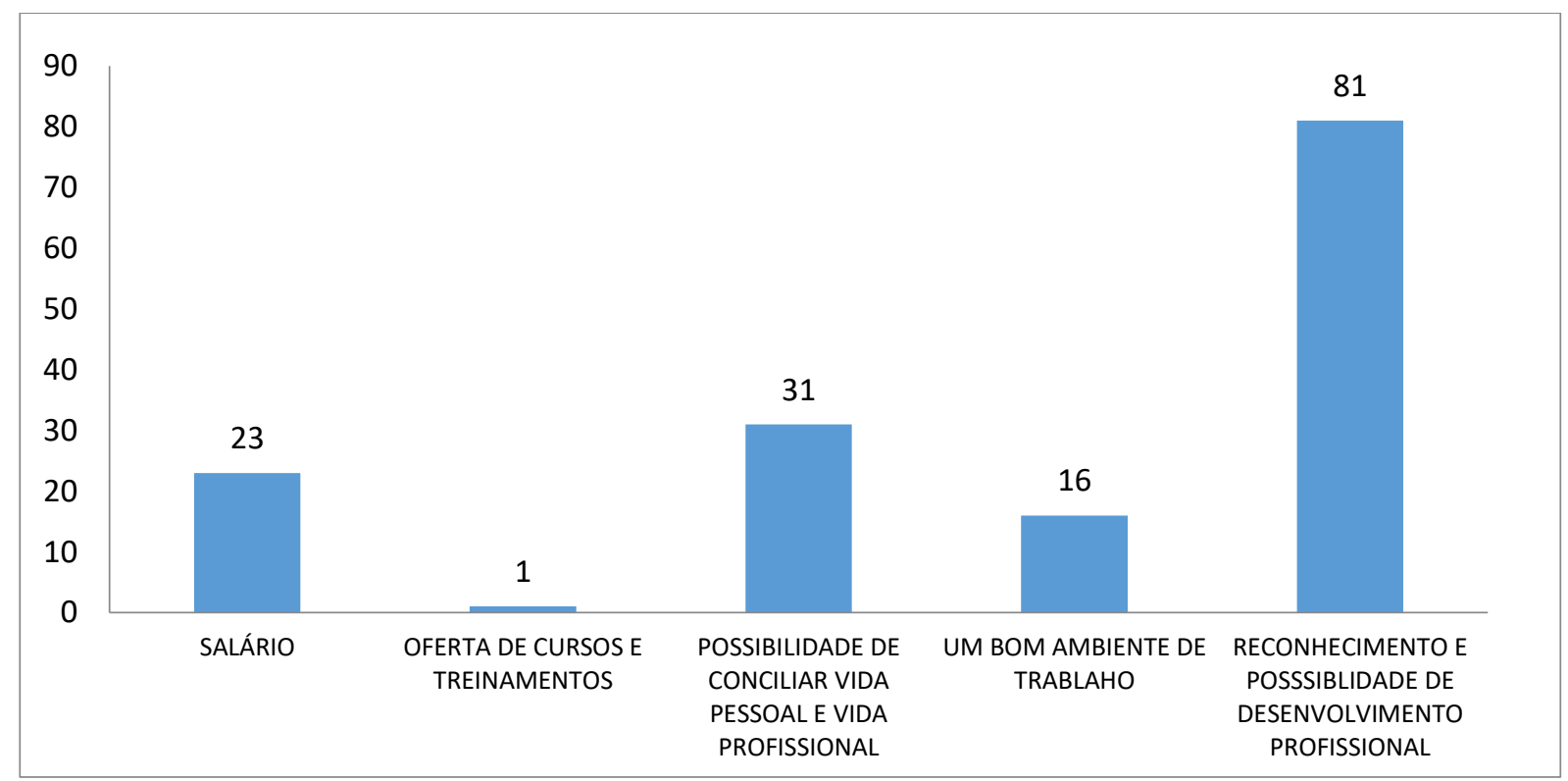

Fonte: Elaborado pelas autoras (2017).

Os participantes da pesquisa apontaram o reconhecimento como um dos principais fatores para a escolha de uma organização e, através do reconhecimento de seu desempenho, eles almejam crescimento profissional, melhores postos de trabalho e novos desafios a serem enfrentados. Grande parte dos profissionais considera o equilíbrio entre trabalho e vida pessoal como ponto mais importante na escolha de uma organização para se trabalhar. Eles não desejam apenas altos salários, querem ser bem-sucedidos, mas sem esquecer da qualidade de vida.

A maioria dos entrevistados acredita na importância da participação dos colaboradores nos processos de tomadas de decisão dentro das organizações, sendo que $23 \%$ afirmaram que os funcionários sempre devem ser convidados para opinar e 52,6\% acreditam que esse convite deve ser feito com frequência, $23,7 \%$ disseram que isso deve ocorrer às vezes e apenas $0,7 \%$ afirmaram que quase nunca os colaboradores devem ser consultados.

Quando questionados sobre o que faria com que deixassem o emprego, as opções mais escolhidas foram: falta de reconhecimento (32,2\%), clima no ambiente organizacional 
$(19,7 \%)$ e impossibilidade de conciliar vida profissional com vida pessoal (17,8\%). Os outros 30,3\% dividem-se em salário, cultura organizacional, cobrança excessiva, equipe, horários e outros.

Para os representantes da geração $Y$, as principais sentenças que melhor caracterizam a obtenção de sucesso são: sensação de realização (34,2\%), ser reconhecido pela comunidade da profissão que atua $(18,4 \%)$, equilíbrio entre vida social e profissional $(17,8 \%)$ e ter amor pela profissão $(17,8 \%)$, seguidos de boa remuneração $(6,6 \%)$, recebimento de várias promoções na carreira $(3,9)$ e não cometer erros naquilo que executa $(1,3 \%)$.

Os entrevistados também opinaram sobre aspectos que gostariam que fossem adotados pelas organizações onde atuam. Boa parte dos entrevistados $(33,6 \%)$ disse esperar por melhores relacionamentos no ambiente de trabalho, demonstrando a necessidade de ações que promovam a integração entre as equipes de trabalho, promovendo melhora no convívio e comunicação entre colegas. Cerca de $27 \%$ dos participantes demonstraram querer que as organizações confiem mais autonomia aos seus colaboradores, reafirmando uma das características apontas pelos autores. Os Y's são estimulados por desafios e oportunidades, receber mais autonomia faz com que se sintam parte importante da organização, capazes de tomar decisões e aprender com isso. A flexibilidade de horários foi apontada por $24,3 \%$ dos participantes como sendo um dos principais pontos a serem adotados pelas organizações, 9,2\% dos entrevistados gostaria de ter mais acesso à mídia digital, enquanto 3,3\% gostaria que as reuniões fossem menos formais e $2,6 \%$ prezaria por menos rigidez no que diz respeito às vestimentas.

Em relação aos fatores a serem considerados na promoção de colaboradores, a maioria dos entrevistados $(67,1 \%)$ afirmou que o principal critério para uma promoção deve ser o desempenho apresentado dentro da empresa, ou seja, a habilidade do indivíduo. O comportamento e as atitudes perante as situações foi apontado por 15,8\% dos participantes, 9,9\% disseram que se deve considerar a formação acadêmica e o conhecimento, enquanto $3,9 \%$ citaram o tempo de atuação na empresa e 3,3\% acreditam em outros fatores.

Ao serem questionados sobre a frequência com que questionam e buscam entender o porquê das ordens de seus líderes, os $Y$ demonstraram sua preocupação em compreender os processos de maneira a promover seu aprendizado bem como seu interesse em participar da análise e escolha dos procedimentos a serem adotados. Dentre os entrevistados, 75,6\% disseram buscar compreender o porquê das ordens de seus superiores, sendo que 47 deles afirmaram fazer isso sempre enquanto 68 indivíduos o fazem com frequência, 18,4\% disseram que às vezes questionam as ordens, 5,3\% responderam que quase nunca agem assim e apenas um dos entrevistados $(0,7 \%)$ disse nunca questionar seu líder.

Quando questionados sobre plano de carreira, 61,2\% dos indivíduos participantes da pesquisa afirmaram que "aquisição de novos conhecimentos e habilidades" seria o item base 
para seu planejamento. $\mathrm{O}$ aumento salarial foi considerado por $11,2 \%$ dos entrevistados como item principal, seguido de aumento de responsabilidades e promoção de cargos, ambos com 8,6\%. Experiência no exterior foi assinalada por 7,9\% dos participantes, enquanto os outros $2,6 \%$ disseram considerar outros fatores.

Foram apresentados, aos participantes da pesquisa, doze possíveis benefícios empresariais dentre os quais eles poderiam escolher cinco que mais Ihes atraíssem. Analisando as respostas, foi possível elencar os cinco benefícios apontados como principais pelos representantes da Geração Y, sendo eles: assistência médica, bolsas de estudo, vale alimentação, previdência complementar e assistência odontológica. Além dos doze possíveis benefícios que foram apresentados como opções, alguns dos entrevistados apontaram outros como: transporte coletivo fretado pela empresa, descontos em estabelecimentos do comércio local, auxílio para aperfeiçoamento profissional, horários mais flexíveis, disponibilidade para viagens técnicas, descontos nos artigos produzidos pela empresa e plano de cargos e salários. As preferências de benefícios apresentadas podem ser observadas no gráfico 2 .

Gráfico 2 - Preferências de benefícios a serem adotados pelas organizações

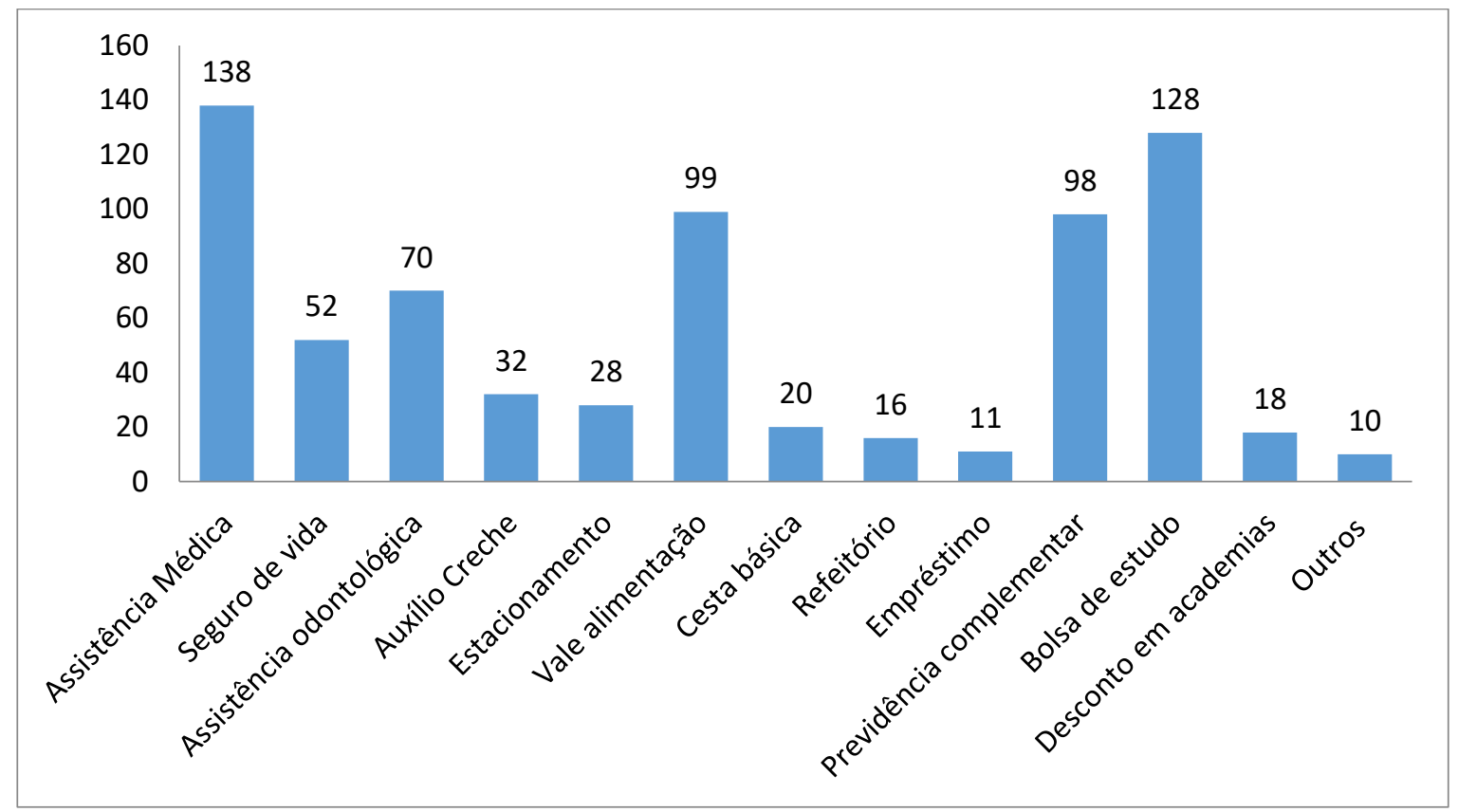

Fonte: Elaborado pelas autoras (2017).

\section{CONSIDERAÇÕES FINAIS}

De acordo com os resultados obtidos foi possível identificar alguns principais fatores de atração e retenção de profissionais pertencentes à Geração Y, sendo eles: reconhecimento e oportunidade de desenvolvimento, possibilidade de conciliação entre vida pessoal e vida profissional e salários adequados. A alternativa que demonstrou maior relevância perante a Geração Y está relacionada ao reconhecimento e desenvolvimento profissional, reafirmando o 
que fora apontado por autores como Oliveira (2009) que afirma que a retenção de jovens da Geração Y está relacionada à novos desafios que promovam o seu crescimento.

Prova da busca constante desses profissionais por conhecimento é o alto nível de escolaridade que fora apresentado por eles através da amostra respondente da pesquisa. Outra característica confirmada está relacionada ao curto período de permanência dentro das organizações, pois quando não percebem reconhecimento de seus esforços os Y's buscam por novas oportunidades. Além disso, esta geração demonstra a necessidade de receber autonomia para tomada de decisões e resolução de problemas nas organizações onde atuam e gostam de sentir-se parte importante destas.

O trabalho com estes profissionais deve ter como base objetivos de curto prazo pois eles demonstram ser imediatistas e possuem certa dificuldade em trabalhar com objetivos a longo prazo. O ambiente organizacional também apresenta grande influência sobre seus comportamentos, por isso a importância em manter um clima agradável e promover a integração entre os colaboradores. Uma boa alternativa é estimular o trabalho em equipe de maneira que promova a troca de conhecimento entre profissionais de diferentes gerações, considerando a existência da variedade geracional trabalhando no mesmo ambiente nos dias atuais.

As ações voltadas à remuneração e promoção destes jovens profissionais deve considerar o desempenho apresentado e suas atitudes perante a organização, além disso, é importante levar em consideração a formação acadêmica e a busca por novos conhecimentos através de cursos profissionalizantes. A adoção destas medidas possibilita às organizações o direcionamento dos trabalhos desenvolvidos por esta geração visando objetivos e reconhecimento em curto prazo, atendendo a característica imediatista destes profissionais e mantendo-os interessados e desafiados dentro da organização.

Fica evidenciada a necessidade de demonstrar a estes jovens profissionais a sua importância dentro da organização e proporcionar-Ihes maior autonomia para tomada de decisões e para resolução de problemas. Estes profissionais consideram a importante conciliar vida pessoal e profissional e são movidos por desafios a curto prazo, considerar estas características no seu gerenciamento pode proporcionar melhor desempenho apresentado por eles.

Diante do estudo é possível orientar os gestores no que diz respeito a necessidade de direcionar as ações voltadas a motivação dos profissionais pertencentes a geração $Y$ através da oportunidade de desenvolvimentos pessoal e profissional. Além disso, o reconhecimento e promoções na carreira devem estar embasados no mérito ao desempenho apresentado e formação acadêmica e profissionalizante, pois foi possível verificar que estes são fatores determinantes para a escolha de oportunidades de trabalho e permanência destes profissionais dentro das empresas. O capital intelectual é um dos fatores determinantes para 
o sucesso das organizações e atender as expectativas dos profissionais da geração $Y$ pode promovê-las significativamente no mercado onde atuam.

\section{REFERÊNCIAS}

BALDIN, Nelma; MUNHOZ, Elzira M. Bagatin. Educação ambiental comunitária: uma experiência com a técnica de pesquisa snowball (bola de neve). 2011. Disponível em: <file:///C:/Users/Usu\%C3\%A1rio/Desktop/3193-8889-1-PB.pdf>. Acesso em: 21/06/2017.

BAUER, Berna. Você sabe o que é geração Y? 2010. Disponível em:

<https://www.bernabauer.com/voce-sabe-o-que-e-a-geracao-y/>. Acesso em: 01/11/2016.

DOS SANTOS, Cristiane Ferreira et al. O processo evolutivo entre as gerações $\mathrm{X}, \mathrm{Y}$ e Baby

Boomers. 2011. Disponível em: <http://www.professores.uff.br/screspo/PSI_P2_artigo9.pdf>. Acesso em: 07/10/2016.

ERICKSON, Tamara J. E agora Geração X? : Como se manter no auge profissional e exercer a liderança plena numa época de intensa transformação. Rio de Janeiro: Elsevier, 2011.

GIL, Antonio Carlos. Como elaborar projetos de pesquisa. 4. ed. São Paulo: Atlas, 2002.

HUNTLEY, Rebecca. The World according to Y: Inside the new adult generation. Sydney: McPherson's Printing Group, 2006.

FONSECA, João José Saraiva da. Metodologia da pesquisa científica. Fortaleza: UEC, 2002. Apostila.

KHOURI, Karim. Liderança é uma questão de atitude. São Paulo: Senac, 2010.

LACOMBE, Francisco José Masset. Recursos Humanos: Princípios e tendências. São Paulo: Saraiva, 2005.

LIPKIN, Nicole; PERRYMORE, April. A Geração Y no trabalho. Como lidar com a força de trabalho que influenciará definitivamente a cultura da sua empresa. Elsevier: Rio de Janeiro, 2010.

MALHOTRA, Naresh K. Pesquisa de marketing. 3.ed. Porto Alegre: Bookman, 2001.

MCCRINDLE, Mark. Understanding Generation Y. Australia: The Australian Leadership Fundation, 2002.

OLIVEIRA, Maria Marly de. Como fazer pesquisa qualitativa. Recife: Ed. Bagaço, 2005.

OLIVEIRA, Sidnei. Geração Y: era das conexões - tempo de relacionamentos. São Paulo: Clube dos autores, 2009.

Geração Y: o nascimento de uma nova versão de líderes. São Paulo: Integrare, 2010. 
PERRONE, Cláudia Maria et al. A percepção das organizações pela geração y. 2012. Disponível em: <https://periodicos.ufsm.br/index.php/reaufsm/article/viewFile/6157/pdf>. Acesso em: 10/11/2016.

WADA, Elizabeth Kyoko; CARNEIRO, Natalie Arruda. As necessidades da geração Y no cenário de eventos empresariais. 2010. Disponível em: <

http://www.eumed.net/ce/2010a/kwac.htm>. Acesso em: 07/10/2016. 